\title{
Student nurses' experiences of how caring and learning is intertwined - A phenomenological study
}

\author{
Camilla Eskilsson $^{1,2}$, Ulrica Hörberg ${ }^{2}$, Margaretha Ekebergh ${ }^{1}$, Gunilla Carlsson ${ }^{1}$ \\ 1. School of Health Sciences, University of Borås, Borås, Sweden. 2. School of Health and Caring Sciences, Linnaeus \\ University, Växjö, Sweden.
}

Correspondence: Camilla Eskilsson. Address: School of Health Sciences, University of Borås, Allégatan 1; 501 90, Borås, Sweden. Email: camilla.eskilsson@hb.se

Received: July 26, 2013

DOI : $10.5430 /$ jnep.v4n2p82
Accepted: August 25, 2013

URL: http://dx.doi.org/10.5430/jnep.v4n2p82

\section{Abstract}

Background: Clinical studies in nursing education ought to create conditions for the students to link theory to praxis. Previous research in this field focuses on the gap between theory and practice, learning environments, supervision and reflection connected to caring and learning. In addition there are studies that propose the concept of learning and caring as intertwined. The aim of this study is to describe how caring and learning is intertwined from a student perspective.

Methods: The study was carried out using Reflective Lifeworld Research (RLR) with a phenomenological approach. Lifeworld interviews were conducted with students after their clinical placement on a Dedicated Education Unit (DEU).

Results: The essential meaning is a movement where caring and learning fall into place which appears in an atmosphere filled with appealing challenges, but has to be sensitive to the students' readiness. The atmosphere depends on their sense of security and how they experience confirming and affirming responses. Encountering the patient means that the students can gain a sense of the whole and the theory falls into place. The results also highlight how the student, in this atmosphere, has a desire to find a new role in a personal style.

Conclusions: The study emphasizes the importance of supporting the students in understanding learning and caring as intertwined and not separated. A dualistic approach could harm the students' aim to get the knowledge embodied. This holistic perspective requires a reflective attitude on caring and learning and has to be further developed in the didactics and supervision.

\section{Key words}

Caring, Learning, Student nurse, Experience, Dedicated education unit, Lifeworld, Didactic, Phenomenological

\section{Introduction}

Nursing education needs to create fertile conditions for students to learn in clinical settings. Learning and caring take place simultaneously in caring contexts and according to Ekebergh ${ }^{[1,2]}$ learning and caring can be understood as intertwined phenomena, but how can learning and caring be intertwined? The purpose of this paper is to study student nurses' experiences of caring and learning as intertwined in a learning environment, which is an important question in terms of the development of teaching strategies in clinical practice in nursing education. 


\subsection{Literature review}

Extensive research has been carried out about learning in clinical practice, the focus of which is primarily on areas such as the gap between theory and practice, learning environments, supervision and reflection on caring and learning. Some examples from each area are presented in the following review.

The importance of overlapping the gap between theory and practice, and of supporting student nurses in feeling comforttable as becoming nurses, are highlighted in a number of studies ${ }^{[3-5]}$. Chuan and Barnett ${ }^{[6]}$ demonstrate that there is a potential for students to develop and learn in learning environments if there are factors that can enhance the learning process. Dedicated Education Units (DEU) as a kind of learning environment, have shown to generate a greater satisfaction among students compared with a traditional supervision model, or traditional units ${ }^{[7,8]}$.

Several studies focus on different supervision models and the impact they have on the nursing students' learning and caring ${ }^{[9]}$. Supervision is carried out as a one-to-one relationship ${ }^{[10]}$ or in pairs of students ${ }^{[11,12]}$, and students can be supervised through peer learning and in that way be supported by each other ${ }^{[13-16]}$.

The learning process in clinical settings is nurtured by reflection and can be performed in groups ${ }^{[17-19]}$, based on patient narratives ${ }^{[20]}$ or through reflective writing ${ }^{[21-23]}$. Reflection has the potential to link theory and practice ${ }^{[24]}$ but the student has a need to receive feedback and guidance from the supervisors in reflection ${ }^{[25]}$. Berglund, Sjögren and Ekebergh ${ }^{[26]}$ combined academic and clinical staff in a group reflection with students in order to further develop the links between the academic field and the caring context.

In addition to the research areas reported above there are also studies that propose the concept of learning and caring as an intertwined phenomenon. These studies address the issue of didactics having the potential to support the students' development in caring contexts ${ }^{[1,2,11,12,27-29]}$.

\subsection{Ontological and epistemological foundation}

Caring and learning, as an intertwined phenomenon, has an ontological and epistemological foundation in caring science and lifeworld theory. Caring science is a body of knowledge for understanding the human being in relation to health, well-being, caring and suffering. Caring science emphasizes the patient's perspective and encompasses existential issues concerning the patient's world. The concept of the lifeworld, based on Husserl's lifeworld theory ${ }^{[30,31]}$ adds a philosophical foundation in order to be able to gain knowledge of the patient's perspective. A lifeworld approach emphasizes the individual's experiences, which thus entails recognizing the world as the patient does, particularly in terms of suffering and well-being. The core of caring, is to support and strengthen the patient's health and wellbeing ${ }^{[32]}$. When the lifeworld perspective relates to learning it entails recognizing the learner's world of experiences as the starting-point for the development of understanding. Learning is an individual process and takes its point of departure in the learner's previous experiences, which become an integral part of this learning process, thus entailing that the learning is dependent on the student's subjective dimension in terms of understanding, values, interests and perspectives.

In order to be able to make sense of experiences and gain new insights the lifeworld has to be reflected upon. In other words the student has to link theory and practice with their own lifeworld as well as to that of the patient. Caring and learning thus entails lifeworld-encounters in order for the student to gain a holistic understanding of the caring ${ }^{\text {[3] }}$. Intertwined caring and learning generates the need for didactics that have the potential of simultaneously supporting caring and learning so as to interweave the two.

The review of the literature indicates a need for further resarch in the learning and caring context as to how caring can nurture learning and vice versa. By using a lifeworld perspective there is a potential to gain knowledge of how student nurses experience caring and learning as intertwined. The knowledge that is generated can contribute to a further development of lifeworld-led didactics being as it is in line with previous research in lifeworld-based care and didactics ${ }^{[1,34]}$. 


\subsection{Aim}

The aim of this study is to describe how caring and learning is intertwined from a student perspective.

\section{Methods}

A focal part of this study is to maintain a genuine desire to discover meanings that will reveal the intertwined phenomenon of caring and learning. Reflective Lifeworld Research (RLR) with a phenomenological approach ${ }^{[35]}$ was chosen in order to study this phenomenon. This approach according to Dahlberg, Dahlberg and Nyström ${ }^{[35]}$ entails openness, bridling and reflective approach to the phenomenon while the researcher searches for meanings. The openness is a genuine willingness to see, listen and try to understand the participants' descriptions of the phenomenon. There is a curiosity, sensitivity and wish to understand something in a new way in this open approach to the phenomenon ${ }^{[36]}$. The process of bridling entails coping with one's own pre-understanding in such a way as to disturb as little as possible the understanding of the phenomenon and also to slow down the process. This process emphasizes the need for having patience, not being too quick or making the indefinite definite too quickly ${ }^{[37]}$.

\subsection{Setting, participants and data collection}

The study, which has a caring science approach and an epistemological foundation in lifeworld theory, was performed at a DEU in an Orthopaedic Clinic. The unit has two aims, one is to support students' learning process and the other is to support the development of excellent care from a caring science perspective. The participating student nurses are on their final clinical placement, which lasts for three weeks. They were supported both by clinical supervisors and a lecturer from the nursing college and were given their own patients to plan for and were to perform nursing care as independently as possible.

The inclusion criteria for the participants were nursing students on their clinical placement in the DEU who were willing to talk about their experiences of caring and learning. Thirteen students from the undergraduate nursing program took part in the study, one male and twelve female, aged between 23 and 39 years. Nine of them participated in group interviews, and three of these also in individual interviews. A further four students participated only in individual interviews.

The lifeworld interviews ${ }^{[35]}$ were conducted after the students had finished the clinical studies and were performed by the first author. Two group interviews were carried out first (four/five participants in each) where the initial question was "Can you tell me about what you have learned by providing care at this unit?" The aim of the group interviews was to stimulate the students' reflection on the phenomenon. It would also help the researcher to further define the phenomenon as a preparation for the individual interviews, where the aim was to gain a greater understanding of the phenomenon. Seven individual interviews were then conducted. The participants had been instructed to have a special situation from the clinical placement in mind, which they had experienced as both caring and learning. When the interview started the initial question was "Can you please tell me about a situation you have experienced as both caring and learning here in the unit". Reenactment was used as a further way of gaining rich descriptions and of recalling memories from the special situation ${ }^{[38,39]}$. When the interview started, the participant recounted the caring situation and then he/she was instructed to show it as a soliloquy. This is characterized by a live monologue in order to arouse memories and to start a process of reflection. In the reenactment the sequence of events is slowed down and the whole scene unfolds in this increased time span. In order to maintain the open and bridling approach, both in the group interviews and the individual ones, clarifying questions were asked such as "Can you tell me more about...?” or "What do you mean by....". The overall goal was to guide the participants to reflect upon the intertwined phenomenon of caring and learning.

\subsection{Data analysis}

In the analysis the same approach of openness, bridling and reflexivity was applied as outlined above ${ }^{[35]}$. In the beginning the transcripts of all the data, from the two sets of interviews were read over and over again in order to gain a sense of "the 
whole" and become familiar with the text. The next sequence involved organizing the text into meaning units. These were read repeatedly in order to transform them to meanings and to further reveal the phenomenon. The data was analyzed as a dialogue between the text and the researcher while all the time remaining focused on the phenomenon, and its meaning, and what it says. During the process there was a movement between close proximity to and distance from the text. The researcher moves between looking at the meaning units as a figure in the foreground, or as part of a background. They were then structured together in clusters based on similarities and differences, and how they related to each other. The phenomenon was highlighted with help of the clusters and the essence could be expressed. The essence is the structure of the meanings or "a phenomenon's style, its way of being" ${ }^{[35]}$ and the aim of the analysis is to describe the essence of the phenomenon and then the phenomenon in all its variations, termed the constituents.

\subsection{Ethical considerations}

The study was approved by the Regional Ethical Review Board in Gothenburg ${ }^{[40]}$ and further conformed to the principles outlined in the Declaration of Helsinki ${ }^{[41]}$. Oral and written information about the study were given to the participants. The voluntary participation and the possibility of withdrawing at any time without explanation, was emphasized. Furthermore confidentiality and protection for the participants' integrity and identity was assured and all the participants gave written consent.

\section{Results}

The essential meaning is a movement where caring and learning fall into place which appears in an atmosphere filled with challenges that appeal to the student nurses. The atmosphere includes sensitivity towards their development and their needs for intertwining theory and practice. Caring and learning meet in a fruitful collaboration in an atmosphere of positive response that offers appealing challenges.

The challenge in both caring and learning has to come at the right time, when one feels one is ready and has a sense of security. The student then has the courage to dare to progress in his/her caring and learning process. In a permissive and secure atmosphere it is possible to face up to exhilarating challenges. Pieces fall into place in the encounter with the patient, and new insights about meaning and coherence occur. Appealing challenges, such as taking more responsibility and gaining greater independence, help to integrate the caring and learning.

A new understanding and confirmation of thoughts and actions are revealed in an atmosphere containing feedback, dialogue and reflection. Responses, both verbatim and through body language, provide guidance about skills and competence. The caring and learning proceeds with the help of confirmation that one is on the right track through a process of continuous dialogue and reflection.

The desire to develop in a new role as a nurse motivates the student to make progress and accept the challenges. The motivation to find one's own personal style is supported in an atmosphere where this desire is understood, where there is room for developing independence and where the possibility for providing care supports the learning. A caring and learning atmosphere can thus be seen as one that is flexible, from providing a secure foundation to providing the opportunity for increasing the student nurse's responsibility and independence on the way to finding a new role and personal style. The following four constituents, Sensing security, Confirming and affirming response, Gaining a sense of the whole and Desiring to find a new role, further elucidate the meaning of the phenomenon.

\subsection{Sensing security}

Supervisors, who exude a sense of security and who have the ability to be able to balance between both monitoring and permitting, actively create an atmosphere of security and support for the student. The overall responsibility of the supervisor offers the students a sense of security. They are given the confidence to take responsibility when they are ready and 
then experience that they learn a great deal. "She [the supervisor] said that I always knew what I was doing // that was good as it meant that I could work independently and still know that if I did something wrong then she would see it".

The introduction to clinical placement creates a safe environment for the students. Explicit and simple routines on the unit provide security and stability for students who might otherwise feel lost in the new context. In this atmosphere they can develop and find their role at their own pace.

Students feel as though they have a "close-knit" group in the interaction with other students. They find security in each other and feel at home in the unit and among the patients. They are willing to accommodate each other's learning by sharing experiences and also by enabling each other to be able to try new situations in nursing care. The sense of security together as a student group creates a permissive atmosphere in which learning is experienced as being pleasurable and joyful.

The students are met by the staff and the patients with an understanding for them being students involved in a learning process. This in turn creates a sense of security in being in an atmosphere containing commitment, tolerance and interest. On the other hand when they are met with disinterest or their supervisor is not available, they are prevented from learning and find difficulties in performing nursing care. There are then no appealing challenges for them but instead they experience feelings of powerlessness, vulnerability and frustration.

The students take their responsibility for the patients seriously and are keen to be prepared and secure in the encounter with the patients. The decisions taken together with physicians create a sense of security for the student and can also provide a calming effect on patients and increase confidence between them. They are given time to prepare themselves in terms of knowledge about the patient so they can feel more independent and can take responsibility for the nursing care. "One becomes more secure and confident in the patient encounters// one has read about the patient and has, well yes, one's own control".

\subsection{Confirming and affirming response}

The students experience responses from patients, staff, supervisors and other students in various ways. They can feel confirmed and gain an insight into them being on the right track or that they have to correct something they do. They can also feel excluded and not be part of the caring and learning environment and thus be frustrated. It is notable that the response is both oral and in body language and helps to create an atmosphere where both caring and learning can proceed. "It felt good that he/l [the physician] took time or at least a short while where we looked at each other and then I felt confirmed"

Their understanding and ability to perform nursing care is challenged and when they are confirmed in being on the right track, they are motivated to take on greater responsibility and be more independent.

The students consider the relationship with the patient to be a part of their caring and learning process. The response given by the patient guides the student to be aware of his/her approach and skills. They describe an ability to understand what is happening in the caring relationship that will guide them to provide good nursing care. "A lot, I think, depends on the contact one has with the patient, how you well, but how you learn how to be in that situation and how you see yourself as a nurse in the future".

When they are excluded and not invited into a dialogue they experience a loss of response and an opportunity to learn can be hindered. They express disappointment and frustration when the supervisor is not available and they are unable to receive feedback. "[The supervisors] didn't have time to see that everything was done properly, they couldn't see what we had found out and there were many times when we didn't get the feedback that we needed". 
The students appreciate and understand the value of reflection, but want it to be given in a flexible way and in a permitting atmosphere. Having structured group reflection, a generally reflective attitude throughout the day, reflecting together with other students to and from work as well as self-reflecting at home provides an opportunity to gain new insights that are valuable in caring. Even if reflection is of great importance for the caring and learning process they express a need to take a break from the reflection sometimes. The students wrote a reflective diary but this was not followed up with the supervisors. It could have been good for them in terms of both the caring and the learning if the supervisors had given them feedback, but now it was more seen as a burdensome duty than a reflective tool. "We wrote in the diaries every day//the idea was that we were to receive the supervisors' reflection and feedback and when we didn't get it// it just fizzled out// we didn't learn anything from using the diaries".

The students are stimulated when the supervisors do not provide ready-made answers and solutions. The students can then answer the questions themselves and are challenged to think for themselves and to dare to take initiative and thus can become empowered and develop their independence. On the other hand they can feel hindered and disturbed when they are provided with ready answers or are corrected too quickly. They lose control and feel disappointed when they are not allowed to think or respond by themselves. They want the supervisor to be flexible and be aware of when they feel ready and prepared. "The student should be allowed to finish his/her sentence before the supervisor starts adding something// they, the supervisors, shouldn't be too quick// I think that you lose a little of your confidence/l and instead be more withdrawn again".

\subsection{Gaining a sense of the whole}

The students experience how theory falls into place and the encounter with the patient has meaning and coherence. Theoretical knowledge and practical training is a foundation but they can never replace the real encounter with the patients. In the interplay with the patient they learn both a caring attitude and practical skills that would have been impossible without the patient. "That's when I learn//when I'm caring// then I learn both how to approach the patient and the practical skills//I have to have a patient so that I can learn how I'm supposed to do it".

The relationship with the patient is sensitive and influenced by the student's own maturity and sense of being ready. When there are moments that the students find difficult to cope with or are unfamiliar with, there is a need to have the supervisors by their side to feel secure. On the other hand when they feel secure in the nursing situation and have an opportunity to be with the patient, to listen and to be patient, they feel satisfied in their nursing performance. They are affected by the patients' limitations and pain, which challenges them to try to ease the suffering, understand and to empathize with their situation. Thus when they feel comfortable and ready to be alone with the patient it is inhibiting having the supervisor in the room. Supervisors have to understand and assess the situation and be able to get the right balance to handle it correctly with just the right amount of supervisory presence. "That's what I think is so good when I'm allowed to go in by myself, that I'm the one who gets the relationship// if the nurse is in there then they'll talk and then I miss the chance for the contact".

The relationship between the patient and the student is strengthened when they meet the same patient a number of days and the latter is in need of a great deal of nursing care. In such a situation they are able to adapt the care more and more individually, while at the same time, in their learning ambition, they try to prioritize what feels the most rewarding to perform or practice in nursing care in order to be prepared as a nurse. They look at their learning needs in the light of the future and can thus sometimes be frustrated in having to care for the same patient for a long time. "You didn't learn so much by being in with her, it was just nursing// if you'd gone back the day after then you wouldn't have learnt anything new".

The students are able to see how the nursing documentation provides a certain picture of the patient, which is then revised when meeting the patient. They feel that it is important to have the encounter as soon as possible in order to be able to obtain as accurate a picture as possible. 
Even if a caring approach can be more or less a part of one's personality and some can exhibit a kind of aptitude for performing caring science there is no short cut for this to become embodied. The student nurses have to meet the patient and in the encounter with the patient a sense of the whole is gained "We read a lot about caring science// but it's first when you meet the patient that you begin to learn".

\subsection{Desiring to find a new role}

Students are driven towards the goal of becoming a nurse in their own personal way. They try to find their own identity as a nurse by having supervisors as role models and choosing what feels right for them when performing nursing care. They look up to and feel comfortable with supervisors who act in a way that is in tune with what they have learnt at university. These supervisors act as guides and are important for them in their development in becoming more mature. Although the supervisors have only been in the background, their actions and attitudes are noticed by the students. They see how the supervisor acts in a thorough and professional manner. They want to live up to this role model, and they also believe that they unconsciously imitate them. "[The supervisor] was very careful, correct and well informed// she was just as we had read about in the course// We wanted to be just like her, we want to be careful and correct, we want to be able to get everything”.

The students strive to perform nursing in their own way in a combination of professionalism and their own personal style. It should be noticeable that it is "just me" who performs nursing and one's own personality is to be preserved even when caring. "[Having the supervisor as a model] helps me// to find out who I am as a carer // you're never exactly like another person, //I am me // it's a mixture of the profession and how you are as a person, that you have // the theoretical knowledge but I still do it my way// it should show when I'm caring”.

In order to find one's own way it is necessary to gain greater independence and confidence for coping with situations by oneself. In order to identify herself in the role one student says: "by being allowed to take responsibility myself, but then also that I was there alone[with the patient], I was the only one who could take care of the situation // there was no one who stood behind me and said no you should think like this or now you should do this, I had to find my own way”.

It can be both liberating and frightening trying to find one's own style and developing into the new role. The atmosphere may contain both security and pressure and can drive them forward to meet the challenges of taking responsibility and solving problems. Some pressure can thus be needed to learn more and to attain the new role. "You have to solve the problem yourself // You're put under a little pressure and I think that you work better when you're put under a little pressure".

The students describe how they mature in a gradual transition from the student role to the nursing role. They are able to cope with more patients than previously, better able to work in a new context and able to take on greater responsibility. Taking more responsibility makes them feel as though they are nurses and theory and practice are more integrated. They gain more understanding of nursing care and in an atmosphere that encourages independence and responsibility a new way of learning in a caring context can arise, which is different to that experienced in other clinical placements. "I've really learnt a lot more// everything is focused round the student and you're given responsibility and then you learn to trust yourself and you develop and you get the information yourself and yes, it's a lot better I think"

The feeling that they are becoming nurses is augmented in the position of power that is experienced in the encounter with the patient. They gain an understanding of the patients' needs for care and can see their own power in their role as a caregiver. It becomes an appealing challenge when attempting to cope with this position of power whilst aiming to benefit the patient. "I felt like I was a nurse/ I felt that I had a sort of, a position there, where I was trusted".

There is a desire and ambition to be prepared for their future role as nurses, and it requires having the confidence and a sense of authority to stand up for their opinion and to take initiative. Encountering staff, physicians or patients fosters them 
to also cope with difficult situations and discussions. "I've noticed that in all parts of the training that I've started to take initiatives and stand up for myself more". Students describe that they can now engage in discussions with physicians in a more mature way than previously. They achieve new insights and can see how things are connected in a new way. They gain an ability to think on their own and courage to question what appears to them to be wrong. As a part of their maturity they can choose the right solutions to problems and gradually see what their future profession will be like.

They finally reflect over how close they are to becoming a nurse and how much this final clinical placement has meant for them. They are amazed how quickly they have grown and matured in learning nursing care. "It only took ten shifts to find the // nurse's role, before it was more of just being a student but now I felt more and more that I would soon be a nurse, it was so close to the final exam, but I also felt that yes, now I know just about what it will be like".

\section{Discussion}

This paper focuses on the phenomenon of intertwined caring and learning and how student nurses describe it. The results show the importance of an atmosphere, which is suitable for students, where they can interact with patients, supervisors and the student group. The support in the student group is a part in the maturing process in the caring context. By reflecting and helping each other in nursing care, they encourage each other to accept challenges and theory and practice fall into place. Other studies have highlighted how support can be performed as peer learning among students or through supervision in pairs ${ }^{[11,12,14]}$.

Reflecting on the phenomenon of the intertwined caring and learning entails allowing a movement to start between these two and allowing the phenomenon to be mirrored by each of them. There is a risk of only focusing on either the one or the other in the interview situation, and thus it was a methodological challenge to maintain the focus on the phenomenon. The current culture in nursing care tends to mainly involve "doing" without reflection. There is also a risk when the learning process is left without reflection and is separated from what is experienced by the student when caring for the patients. Merleau-Ponty ${ }^{[42]}$ described how the human existence and the environment is intertwined. Both depend on and influence each other. We are all influenced by the world around us while we also influence the world. In that way we cannot separate our existence from the world that we live in. People experience phenomena as wholes ${ }^{[43]}$ but also as individual aspects in the complex whole. The intertwined phenomenon of caring and learning can be seen in the same way as the human existence in the world, depending on and influencing each other. By using Merleau-Ponty ${ }^{[42,43]}$ we can also explain this phenomenon as an interaction between caring and learning, characterized by a movement between the background and the figure. Caring creates a background for learning in some situations, which can then appear as a figure and the learning process is activated in a fruitful way. On the other hand learning becomes the background for caring in other situations, which are then the focus of the student's consciousness and actions. It is however through the learning, which provides the background that the student is able to care. This movement keeps caring and learning together, but the focus varies depending on the purpose with the different situations in practice.

The current perspective in nursing care is tending to be dualistic, which can harm the understanding of caring and learning. If, for example, theory and practice or the nursing education and the clinic were divided there would be no sense of the whole and it would be difficult for the student to experience that knowledge falls into place and to experience it as embodied knowledge. In supervision attention should be paid to intertwining caring and learning through reflection and with a lifeworld perspective. There is a challenge for both students and supervisors in the process of avoiding all kinds of dualism.

If the atmosphere is to be favorable for performing nursing care and for the knowledge to be embodied then sensitivity for the student's lifeworld is needed. The atmosphere has to be characterized by security where challenges do not generate fear but instead are appealing to the students. The challenges that are presented in nursing care are coped with by the students when they are given responsibility and try to perform the nursing care themselves. 
The students expressed their satisfaction and astonishment about how quickly they developed their responsibility, confidence and their future role. Even if they were sometimes pressurized to solve situations themselves, it was generally felt that the time was right for them and they liked accepting the challenges. Gadamer ${ }^{[36]}$ points out how one's own understanding has to be challenged in order to achieve new understanding. The students demonstrate courage in challenging their previous understanding and thus broaden their horizon. The crucial role of the supervisors is particularly noticeable. Their support means security for the students and can be experienced both when the supervisor is present or not. The student has to be able to trust that he/she can always receive the support and get the opportunity to be able to reflect together with the supervisor. Supervision can be seen as an art in being sensitive towards the students' lifeworld and being able to support the student individually to meet his/her needs. The findings of Holst and Hörberg ${ }^{[11,12]}$ indicate the importance of students having the opportunity to independently carry out caring. Reflection, which is a part of the supervision, plays a decisive role in the integration of theory and practice. Moreover both caring and learning are seen as emanating from a lifeworld perspective, i.e. emanating from the one who experiences the caring or learning.

In the encounter with the patients the student can gain a sense of theory and practice as a whole and thus the time spent with the patient is valuable for the students' learning as well as that spent with the supervisor ${ }^{[44]}$. Being in a caring context provides the students with the opportunity of developing an understanding of the patient and learning how to meet his/her needs. This, however, requires a reflective attitude that needs to be supported in the supervision.

The students endeavor to integrate knowledge and experiences from the caring context, which enable the development of embodied knowledge. This process creates the foundation for a personal style of performing nursing care, in comparison with Merleau-Ponty ${ }^{[42,43]}$. The personal style becomes visible through their lived bodies, which entails their whole presence in caring encounters, both verbal and nonverbal expressions. In this developing process it is of crucial importance with reflection on actions and experiences. The students need a powerful support from their supervisors in this reflection that includes awareness about caring and learning being intertwined ${ }^{[1]}$. Students have to be taken seriously and their lived experiences of care not be neglected ${ }^{[45]}$. Reflection based on their lived experiences and on the patients' narratives contributes to them gaining new insights. The results show that different types of reflection are important for the student to be able to integrate caring and learning, which calls for strategies to make reflection be a natural part of the learning process in caring contexts in order for the knowledge to be embodied.

It is a methodological challenge to maintain an open approach to the phenomenon and to bridle one's preunderstanding ${ }^{[35]}$. The issue is about not making the indefinite definite too quickly throughout the whole process ${ }^{[37]}$, but to really think through what the meaning is in what the informant says about the phenomenon. The act of bridling can be similarly described as a slowing down in the process of understanding and not taking anything for granted. By using reenactment a further perspective could entail that the phenomenon was studied through a situation that was remembered and brought to life again and thus the focus on the phenomenon could be maintained in the interview. The research team and doctoral colleagues assisted in reviewing the manuscript in the analysis phase several times and thus contributed to the analysis process. The results are presented in the form of the essence of the phenomenon and its constituents in accordance with the principles of RLR ${ }^{[35]}$, and can thus be seen in a wider perspective and be appropriate even for other contexts where student nurses are in clinical settings.

\section{Conclusion}

The result emphasizes the importance of supporting the students in understanding caring and learning as being intertwined so that the knowledge can be embodied and they can find their personal style. An atmosphere that is characterized by challenges that appeal to the students and that are presented at the right time is needed. If the atmosphere lacks security, a sense of support and feedback to the student, he/she is prevented from developing in their caring and learning. A similar hindrance can occur if caring and learning is seen as separate parts and not intertwined. Caring can then be just a "doing" or an imitation of the supervisor's behavior, without any reflection. Learning can be a concern for the student him/herself 
and not a part of good nursing care. The patient can be the means for the student to gain his/her goal to learn while it should always be that it is the patient that is the goal for the nursing care. It appears to be important to create a reflective atmosphere where the students are supported in seeing the whole complexity of caring and learning and how they depend on each other. The students have to be allowed to take the challenge of meeting the patients in a caring context and to become more and more independent.

To see caring and learning as being intertwined might be a challenge for both students and supervisors and can be seen as a change in perspective. In this holistic perspective on caring and learning, we have the same approach as in caring science. An atmosphere that contains this kind of holistic perspective can contribute to making caring more learning and learning more caring, being as they are intertwined. A holistic view is, however, often threatened by a dualistic perspective, but can be maintained when there is time to allow caring to be reflected upon in terms of learning and vice versa. This perspective will have consequences for education and for clinical settings as well. It entails, for example, developing a conscious attitude of there being a learning moment in every caring situation and caring potential in every learning activity. Lifeworld led didactics can further be developed when caring and learning can be grasped as being intertwined and seen as one phenomenon in all its complexity and variations. The goal for learning environments is thus to create conditions for an atmosphere where the students can get the knowledge embodied and find their personal style. It requires support not only for the students but for the supervisors as well, in order to understand and reflect on the intertwined phenomenon of caring and learning.

\section{References}

[1] Ekebergh M. Developing a didactic method that emphasizes lifeworld as a basis for learning. Reflective Practice. 2009 ; $10: 51-63$. http://dx.doi.org/10.1080/14623940802652789

[2] Ekebergh, M. A learning model for nursing students during clinical studies. Nurse Education in Practice. 2011; 11: 384-389. PMid:21489878 http://dx.doi.org/10.1016/j.nepr.2011.03.018

[3] Jerlock M, Falk K, Severinsson E. Academic nursing education guidelines: tool for bridging the gap between theory, research and practice. Nursing \& Health Sciences. 2003; 5: 219-228. http://dx.doi.org/10.1046/j.1442-2018.2003.00156.x

[4] Landers, M.G. The theory-practice gap in nursing: the role of the nurse teacher. Journal of Advanced Nursing. 2000; 32: 1550-1556. PMid:11136425 http://dx.doi.org/10.1046/j.1365-2648.2000.01605.x

[5] Ekebergh M. Tillägnandet av vårdvetenskaplig kunskap: reflexionens betydelse för lärandet (AcquiringCaring Science Knowledge - The importance of reflection for learning) PhD thesis. Åbo Akademi, Institutionen för vårdvetenskap (Åbo Academy, Health Care Sciences) 2001.

[6] Chuan, O.L, Barnett, T. Student, tutor and staff nurse perceptions of the clinical learning environment. Nurse Education in Practice. 2012; 12: 192-197. PMid:22277167 http://dx.doi.org/10.1016/j.nepr.2012.01.003

[7] Rhodes M.L, Meyers,C.C, Underhill M.L. Evaluation outcomes of a dedicated education unit in a baccalaureate nursing program. Journal Of Professional Nursing: Official Journal Of The American Association Of Colleges Of Nursing. 2012; 28 : $223-230$. PMid:22818192 http://dx.doi.org/10.1016/j.profnurs.2011.11.019

[8] Shake E.E, Dedicated Education Units: Do they improve student satisfaction? PhD thesis. University of South Carolina 2010.

[9] Hellström-Hyson E, Mårtensson G, Kristofferzon M.-L. To take responsibility or to be an onlooker. Nursing students' experiences of two models of supervision. Nurse Education Today. 2012; 32: 105-110. PMid:21388721 http://dx.doi.org/10.1016/j.nedt.2011.02.005

[10] Luhanga F.L, Billay D, Grundy Q, Myrick F, Yonge O. The one-to-one relationship: is it really key to an effective preceptorship experience? A review of the literature. International Journal of Nursing Education Scholarship. 2010; 7: article 21: 1-15.

[11] Holst H, Hörberg, U. Students' learning in an encounter with patients - supervised in pairs of students. Reflective Practice. 2012; 13: 693-708. http://dx.doi.org/10.1080/14623943.2012.670623

[12] Holst H, Hörberg, U. Students learning in clinical practice, supervised inpairs of students - a phenomenological study. Journal of Nursing Education and Practice. 2013; 3: 113-124. http://dx.doi.org/10.5430/jnep.v3n8p113

[13] Chojecki, et al. Perceptions of a peer learning approach to pediatric clinical education. International Journal of Nursing Education Scholarship. 2010;7: article 39: 1-14.

[14] Christiansen A, Bell A. Peer learning partnerships: exploring the experience of pre-registration nursing students. Journal Of Clinical Nursing. 2010;19:803-810. PMid:20500324 http://dx.doi.org/10.1111/j.1365-2702.2009.02981.x

Published by Sciedu Press 
[15] Ruth-Sahd L.A. Student nurse dyads create a community of learning: proposing a holistic clinical education theory. Journal of Advanced Nursing. 2011; 67: 2445-2454. PMid:21615457 http://dx.doi.org/10.1111/j.1365-2648.2011.05690.x

[16] Kling V.G. Clinical leadership project. The Journal Of Nursing Education. 2010; 49: 640-643. PMid:20795613 http://dx.doi.org/10.3928/01484834-20100831-02

[17] Flateland, S, Kristiansen A, Söderhamn U. Nursing students' learning -- learning in practice trough participation in a reflection group [Norwegian]. Nordic Nursing Research / Nordisk Sygeplejeforskning. 2011; 13: 5-18.

[18] Holmlund K, Lindgren B, Athlin E. Group supervision for nursing students during their clinical placements: its content and meaning. Journal of Nursing Management. 2010; 18: 678-688. PMid:20840362 http://dx.doi.org/10.1111/j.1365-2834.2010.01157.x

[19] Lindgren B, Athlin E. Nurse lecturers' perceptions of what baccalaureate nursing students could gain from clinical group supervision. Nurse Education Today. 2010; 30: 360-364. PMid:19818540 http://dx.doi.org/10.1016/j.nedt.2009.09.008

[20] Gidman J. Listening to stories: Valuing knowledge from patient experience. Nurse Education in Practice. 2012, http://dx.doi.org/10.1016/j.nepr.2012.09.006. http://dx.doi.org/10.1016/j.nepr.2012.09.006

[21] Montagna L, Benaglio C, Zannini L. Reflective writing in nursing education: background, experiences and methods. Assistenza Infermieristica E Ricerca: AIR 2010; 29: 140-152. PMid:21188863

[22] Harrison P.A, Fopma-Loy J.L. Reflective Journal Prompts: A Vehicle for Stimulating Emotional Competence in Nursing. Journal of Nursing Education. 2010; 49: 644-652. PMid:20669871 http://dx.doi.org/10.3928/01484834-20100730-07

[23] Ball E.C. Annotation an effective device for student feedback: a critical review of the literature. Nurse Education in Practice. 2010; 10: 138-143. PMid:19560401 http://dx.doi.org/10.1016/j.nepr.2009.05.003

[24] Asselin M.E. Using Reflection Strategies to Link Course Knowledge to Clinical Practice: The RN-to-BSN Student Experience. Journal of Nursing Education. 2011; 50: 125-33. PMid:21210605 http://dx.doi.org/10.3928/01484834-20101230-08

[25] Hong L.P, Chew L. Reflective practice from the perspectives of the bachelor of nursing students: a focus interview. Singapore Nursing Journal. 2008;35:42-48.

[26] Berglund M, Sjögren R, Ekebergh M. Reflect and learn together - when two supervisors interact in the learning support process of nurse education. Journal of Nursing Management. 2012; 20: 152-158. PMid:22380410 http://dx.doi.org/10.1111/j.1365-2834.2011.01368.x

[27] Galvin K.T. Todres L. Research based empathic knowledge for nursing: A translational strategy for disseminating phenomenological research findings to provide evidence for caring practice. International Journal of Nursing Studies. 2011; 48: 522-530. PMid:20863496 http://dx.doi.org/10.1016/j.ijnurstu.2010.08.009

[28] Hörberg U, Ozolins L.-L, Ekebergh M. Intertwining caring science, caring practice and caring education from a lifeworld perspective - two contextual examples. International Journal of Qualitative Studies on Health and Well-Being. 2011; 6: 1-6. PMid:22171223 http://dx.doi.org/10.3402/qhw.v6i4.10363

[29] Hörberg U, Ozolins L-L. Film as Support for Promoting Reflection and Learning Caring Science. Indo-Pacific Journal of Phenomenology. 2012; 12: 1-12.

[30] Husserl E. The crisis of European sciences and transcendental phenomenology : an introduction to phenomenological philosophy. Northwestern University studies in phenomenology \& existential philosophy. Evanston: Northwestern U.P, 1978,

[31] Husserl E. Experience and judgment: investigations in a genealogy of logic. Northwestern University studies in phenomenology \& existential philosophy. Evanston: Northwestern Univ. Press, 1973.

[32] Dahlberg K, Segesten K. Hälsa och vårdande : i teori och praxis (Health and caring in theory and praxis) Stockholm: Natur \& kultur, 2010.

[33] Ekebergh M. Vårdvetenskapens didaktik (Caring Science Didactic). In Vårdvetenskapliga vägskäl (Crossroads in Caring Science). Berglund M, Johansson A, Roxberg Å. Institutionen för vårdvetenskapligt och socialt arbete, Växjö universitet. 2008; 25-48.

[34] Ekebergh M. Lifeworld-based reflection and learning: a contribution to the reflective practice in nursing and nursing education. Reflective Practice. 2007; 8: 331-343. http://dx.doi.org/10.1080/14623940701424835

[35] Dahlberg K, Dahlberg H, Nyström M. Reflective lifeworld research.Lund: Studentlitteratur. 2008.

[36] Gadamer H.-G.Truth and method. London: Sheed and Ward. 1979.

[37] Dahlberg K, Dahlberg H. To not make definite what is indefinite: A phenomenological analysis of perception and its epistemological consequences in human science research. The Humanistic Psychologist. 2003; 31: 34-50. http://dx.doi.org/10.1080/08873267.2003.9986933

[38] Carlsson G, Drew N, Dahlberg K, Lützen K. Uncovering tacit caring knowledge. Nursing Philosophy. 2002 ; 3: 144-151. http://dx.doi.org/10.1046/j.1466-769X.2002.00092.x

[39] Drew N. Reenactment interviewing: a methodology for phenomenological research.Journal of Nursing Scholarship. 1993. 25(4): 345-351. http://dx.doi.org/10.1111/j.1547-5069.1993.tb00270.x

[40] Regional Ethical Review Board in Gothenburg http://www.epn.se/en/start/startpage/(25 July 2013, date last accessed) 
[41] Declaration of Helsinki, World Medical Association Declaration of Helsinki, 2008. http://www.wma.net/en/30publications/10policies/b3/ (22 July 2013, date last accessed)

[42] Merleau-Ponty M. The visible and the invisible: followed by working notes. Northwestern University studies in phenomenology \& existential philosophy. Evanston: Northwestern Univ.Press,1968/1948.

[43] Merleau-Ponty, M. Phenomenology of perception. Routledge Classics. London: Routledge. 2002/1945.

[44] Warne T. et al. An exploration of the clinical learning experience of nursing students in nine European countries. Nurse Education Today 2010;30:809-815. PMid:20409620 http://dx.doi.org/10.1016/j.nedt.2010.03.003

[45] Solvoll B, Heggen K.M. Teaching and learning care--exploring nursing students' clinical practice. Nurse Education Today. 2010; 30: 73-77. PMid:19581026 http://dx.doi.org/10.1016/j.nedt.2009.06.003 